\title{
Space-Time Distribution Laws of Tunnel Excavation Damaged Zones (EDZs) in Deep Mines and EDZ Prediction Modeling by Random Forest Regression
}

\author{
Qiang Xie ${ }^{1,2}$ and Kang Peng ${ }^{3,4}{ }^{3,4}$ \\ ${ }^{1}$ School of Civil Engineering, Central South University, Changsha 410075, China \\ ${ }^{2}$ Hunan City University, Yiyang 413000, China \\ ${ }^{3}$ State Key Laboratory of Coal Mine Disaster Dynamics and Control, Chongqing University, Chongqing 400044, China \\ ${ }^{4}$ College of Resources and Environmental Science, Chongqing University, Chongqing 400044, China
}

Correspondence should be addressed to Kang Peng; pengkang@cqu.edu.cn

Received 19 December 2018; Revised 23 April 2019; Accepted 7 May 2019; Published 29 May 2019

Academic Editor: Rosario Montuori

Copyright (C) 2019 Qiang Xie and Kang Peng. This is an open access article distributed under the Creative Commons Attribution License, which permits unrestricted use, distribution, and reproduction in any medium, provided the original work is properly cited.

\begin{abstract}
The formation process of EDZs (excavation damaged zones) in the roadways of deep underground mines is complex, and this process is affected by blasting disturbances, engineering excavation unloading, and adjustment of field stress. The range of an excavation damaged zone (EDZ) changes as the time and space change. These changes bring more difficulties in analyzing the stability of the surrounding rock in deep engineering and determining a reasonable support scheme. In a layered rock mass, the distribution of EDZs is more difficult to identify. In this study, an ultrasonic velocity detector in the surrounding rock was used to monitor the range of EDZs in a deep roadway which was buried in a layered rock mass with a dip angle of $20-30^{\circ}$. The space-time distribution laws of the range of EDZs during the excavation process of the roadway were analyzed. The monitoring results showed that the formation of an EDZ can be divided into the following stages: (1) the EDZ forms immediately after the roadway excavation, which accounts for approximately $82 \%-95 \%$ of all EDZs. The main factors that affect the EDZ are the blasting load, the excavation unloading, and the stress adjustment; (2) as the roadway excavation continues, the range of the EDZs increases because of the blasting excavation and stress adjustment; (3) the later excavation zone has a comparatively larger EDZ value; and (4) an asymmetric supporting technology is necessary to ensure the stability of roadways buried in layered rocks. Additionally, the predictive capability of random forest modeling is evaluated for estimating the EDZ. The root-mean-square error (RMSE) and mean absolute error (MAE) are used as reliable indicators to validate the model. The results indicate that the random forest model has good prediction capability $(\mathrm{RMSE}=0.1613$ and $\mathrm{MAE}=0.1402)$.
\end{abstract}

\section{Introduction}

The geo-stress level has a close relationship with the fracture of surrounding rock and the onset of rock dynamic disasters in underground engineering [1-8]. In general, the geo-stress consists of two aspects: the vertical stress and horizontal stress. The vertical stress is rooted in the gravity of the overlying strata and increases by $27 \mathrm{MPa}$ per kilometer with buried depth. The horizontal stress is influenced by the geological structure and has an irregular increasing trend with buried depth [9-13]. Consequently, the excavation of deep roadways can disturb the geo-stress field and lead to a redistribution of the initial stress. As a result, the radial stress decreases, and the tangential stress increases [13]. The deep rocks distributed in the area of redistribution stress are called engineering surrounding rocks. Many underground mines have stepped into the deep mining ranks. The mining depth is approximately $1000-2000 \mathrm{~m}$, and the redistribution stress level is high. The deep buried rocks are subjected to high static stress and excavation disturbances, such as blasting dynamic loading and excavation unloading, which can induce weakening in the engineering rocks $[14,15]$, as shown in Figure 1.

Under the coupled action of high stress, blasting vibration, and unloading disturbance, the cracks in surrounding 


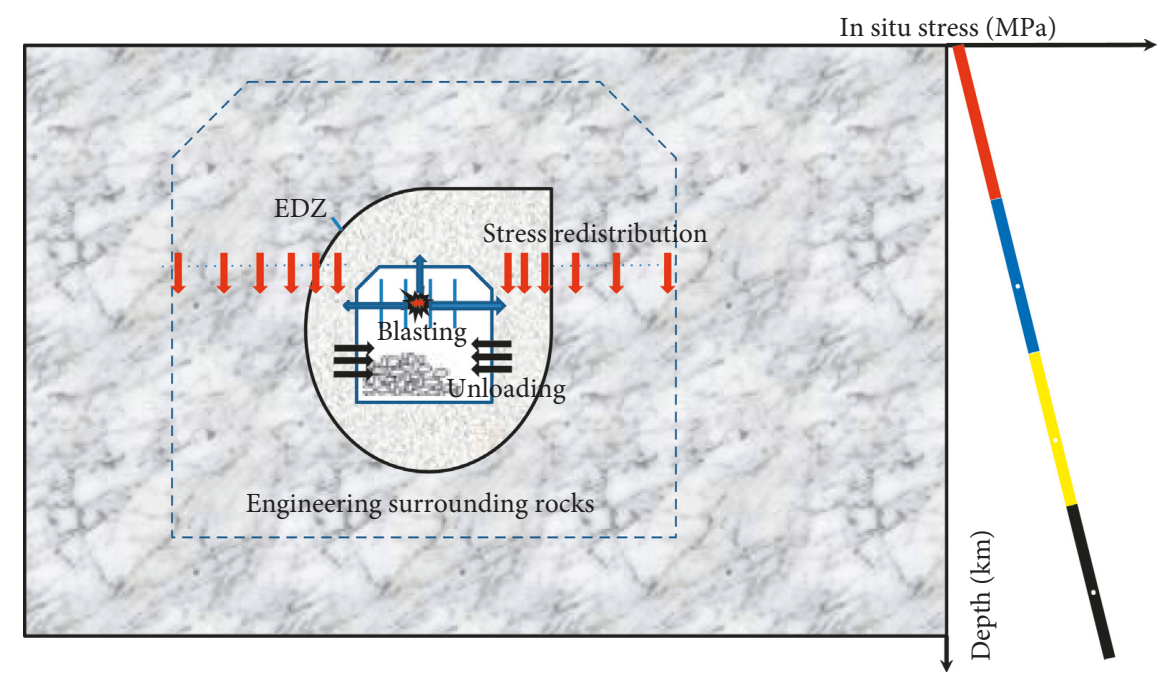

Figure 1: A static-dynamic stress situation of underground engineering surrounding rocks.

rocks are induced to expand and the strength is weakened forming an unstable area $[1,16-18]$. The unstable area is also called the excavation damage zone (EDZ) $[14,15]$. The blasting excavation that influences the surrounding rocks can be better understood if the size of the EDZ is measured accurately. In addition, details about the size of the EDZ can provide a theoretical basis for supporting parameter design for underground roadways.

Theoretical analysis, numerical simulations, and field tests are commonly used to predict the size of an EDZ in underground engineering. Theoretical analyses are based mainly on different constitutive models and failure criteria, such as Mohr-Coulomb and Hoek-Brown failure criteria [19], which do not consider the effect of intermediate principal stress on EDZs. The Drucker-Prager criterion and unified strength theory have been used to solve the elasticplastic problem of surrounding rocks in underground roadways $[20,21]$. In general, the results of theoretical analyses have large gaps compared with results from field tests. Numerical simulation and field testing are two effective methods in the stability analysis of rock engineering [22-25] that have been widely applied to investigate the distribution ranges of EDZs. The size of an EDZ is a function of time and moisture and has a significant effect on its development, which is affected by rock mass structure, initial stress, and tunnel radius [26-29]. Moreover, considering that it is timeconsuming to conduct numerous tests to characterize the EDZ, supervised machine learning algorithms based on random forest [29-32] models are proposed in this study, and the EDZ is predicted as the output variable.

As discussed above, many studies on the size of EDZs have been carried out. However, the time and space distribution regulation of EDZs has rarely been the focus. Thus the roadways buried at $550 \mathrm{~m}$ in an underground mine were chosen to study the time-space distribution laws of EDZs. The results of this study showed that the proposed analytical solutions were able to predict damage regions. Moreover, these findings can provide measures to control damage zones and can also provide theoretical guidance for underground tunnel excavation and support. Lastly, random forest [33] models are adopted to obtain the nonlinear relationship between the EDZ and various predictors. Then the developed model is assessed with cross validation, and the performance of the proposed model is compared with multiple linear regression [34].

\section{Field Testing Scheme}

The section shape of the roadway being tested is a threecentered arch type. The surrounding rock lithology of the roadway is violet red slate, which obviously has an inclined bedding structure. The uniaxial compressive strength of an intact slate specimen that is $50 \mathrm{~mm}$ in diameter and $100 \mathrm{~mm}$ in height is $107 \mathrm{MPa}$, which categorizes very strong rock [29]. The dip angle of the inclined stratum is approximately $20-30^{\circ}$. From a geo-stress survey, the value of the vertical stress is much smaller than the horizontal stress; the direction of the maximum principle stress, $\sigma_{1}$, is horizontal and the direction of the minimum principle stress, $\sigma_{3}$, is vertical. Under the special buried environment of the roadway, roof caving and floor heaving are two main rock failure types. Thus, it is necessary to carry out studies on the regular distribution of EDZs and the supporting design, as shown in Figure 2.

At present, many methods have been used to determine the size of EDZs in the field [29-32]. In these studies, a single-hole wave velocity monitoring method was applied. The primary device was a BA-II ultrasonic crack detector, whose main components were a host computer, a water plugged up block, a water pipe, an ultrasonic source probe, and receiving probes. A simple illustration of the principle of the single-hole wave velocity monitoring technique is shown in Figure 3. Seven boreholes were chosen for measuring the size of an EDZ on a section of the roadway. The testing borehole 6 was used to monitor the wave velocity. The main scheme of the technique is outlined in Figure 3.

The source and receiving probes were inserted into a borehole, and then water was injected into the borehole, and 


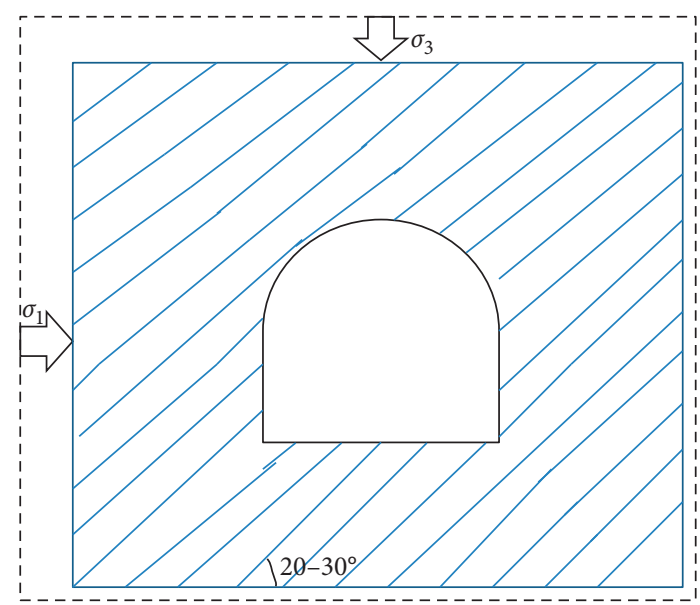

Figure 2: A geo-stress situation and bedded rock strata.

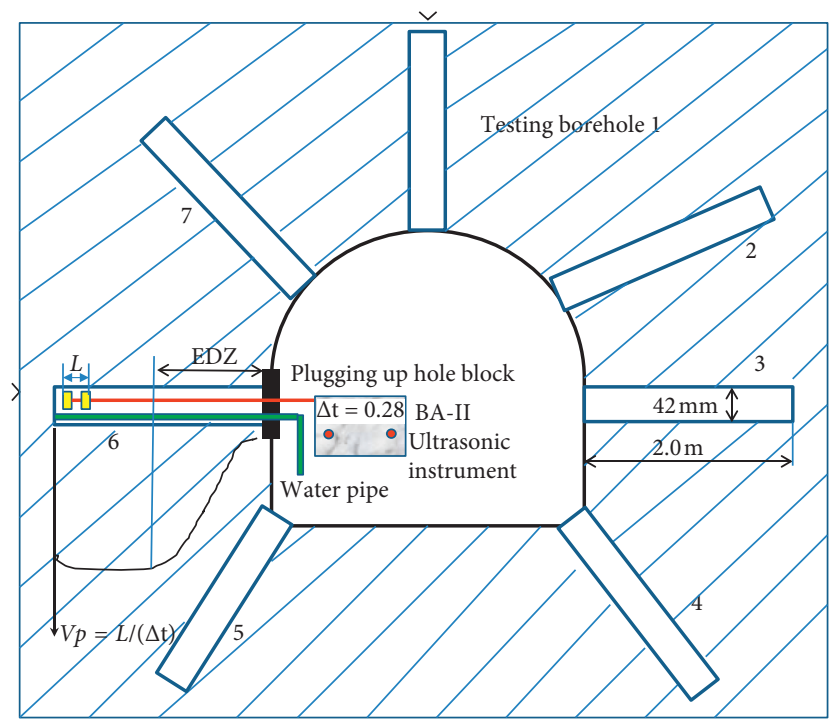

FIgURE 3: Arrangement of the monitored boreholes around the roadway.

the borehole was filled until the testing was finished. The source probe was triggered by ultrasonic waves, which were received by the receiving probe. The difference between the generation time of the source probe and the arrival time of the receiving probe was the travel time, $\Delta t$, of the ultrasonic wave, and the distance from the source probe to the receiving probe was the travel distance, $L$, of the ultrasonic wave; the travel distance of the BA-II ultrasonic crack detector was $140 \mathrm{~mm}$. The formulation of the wave velocity in the surrounding rocks at each monitored point of the borehole can be expressed as

$$
V_{p}=\frac{L}{(\Delta t)} .
$$

The ultrasonic velocity decreases with the development of fractures in the surrounding rocks. That is, the velocity was high if the surrounding rocks were intact; otherwise, the velocity was low. Hence, the thicknesses of the EDZ around a roadway can be determined by analyzing the sudden change point in the wave velocity, as shown in Figure 3 (the black line is near borehole 6).

\section{Measurement Results and Application}

Three typical sections of the roadway are chosen in this study. The distribution of the chosen sections is shown in Figure 4 . The total length of the drilling roadway is $40 \mathrm{~m}$, and the chosen sections are located at $10 \mathrm{~m}, 20 \mathrm{~m}$, and $30 \mathrm{~m}$ of the roadway. The excavation direction of the roadway is from Section 1 to Section 2. The excavation speed of the roadway is approximately $2.5 \mathrm{~m}$ per day. EDZs in every section were detected for 20 days. The interval of detection was 4 days.

The detailed relationship between the wave velocity and the length of the testing holes is shown in Figures 5-7. There is a sudden change point in the wave velocity for each borehole, that is, the size of the EDZ is clear and quantitative. According to the $V_{p}-L$ curves, the ultrasonic velocity increased with the increase in borehole depth. First, the wave velocity had lower values because of the large number of cracks induced in the rocks near the roadway boundary. The wave velocity in the surrounding rocks near the boundary of the roadway was approximately $1500-2000 \mathrm{~m} / \mathrm{s}$. In contrast, the wave velocity reached a high and stable value when the monitoring points were located considerably far from the roadway boundary, which was approximately $3500-3800 \mathrm{~m} / \mathrm{s}$. The location of the sudden velocity change point is the extent of the EDZ.

The size of the EDZ as observed from different holes at the same section is different. The EDZ at the top left corner (borehole 7) had the largest value, and those at the roof and top right corner (borehole 1 and borehole 2) also had greater values, which are the main reasons to for roof caving. The size of the EDZ at the lower left corner (borehole 4) was also over $110 \mathrm{~mm}$ and was much larger than that of other boreholes, such as borehole 3 , borehole 5 , and borehole 6, which induced the floor heave. An asymmetric distribution regulation of EDZs in the layered rocks was found, as shown in Figures 5(d), 6(d), and 7(d). The dip angle of the rock layer has a large influence on the EDZs in an underground space. After excavation of the roadway, the surrounding rocks were impacted by blasting dynamic loads and the unloading effect; thus, the initial EDZ formed. Then the concentration of $\sigma_{1}$ occurred on the top and bottom floors of the roadway, and the EDZ size increased slightly. Because of the small value of $\sigma_{3}$, the EDZ size near the walls of the roadway also had small values. The EDZ size for different sections had similar developmental progress. In addition, if the initial size of the EDZ was small, the wave velocity of rocks located in the range of the EDZ was comparatively high.

A clear time distribution for EDZs was observed, as shown in Figure 8. The observation of the EDZs for each borehole lasted for 20 days. For a single testing borehole, the EDZ size increased with the continuous basting excavation of the roadway. However, the increase in EDZ extent was limited to approximately $5-18 \%$ of the initial size of the EDZ. The increment of the EDZ increased with an increase in the initial EDZ size. 


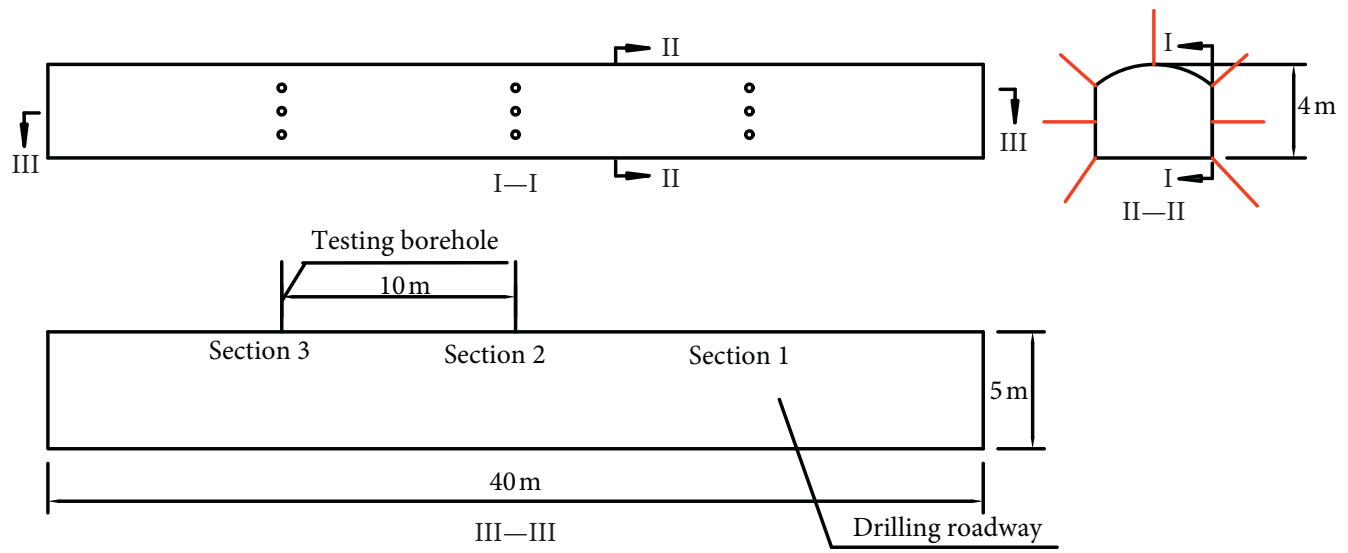

FIGURE 4: Field testing scheme.

In general, the size of the EDZs in different sections, in order from the largest to the smallest, is as follows: Section 3, Section 2, and Section 1, as shown in Figure 9. The order of the EDZ size is opposite of the excavation order of the sections. The EDZ of the later section is affected by the stress concentration and excavation blasting of the previous section.

Bolts with a $2 \mathrm{~m}$ length were used to support the roadway. However, roof caving and floor heaving often occurred in the roadway. Thus, based on the distribution regular of the EDZ, the supporting technology was modified as follows: the length of the bolts was changed from $2.0 \mathrm{~m}$ to $2.5 \mathrm{~m}$ at the top left corner and the lower left corner of the roadway and the length of bolts was kept at $1.5 \mathrm{~m}$ at the other positions. The number at the top left corner and the lower left corner of the roadway was changed from 1 to 3 , as shown in Figure 10. After these changes, the occurrence of roof caving and floor heaving was reduced.

\section{EDZ Prediction by the Random Forest Model}

4.1. Data Set and Descriptive Analysis. In this study, the developed random forest method was used to obtain the predictive results. A group of 63 experimental results were utilized to evaluate the feasibility of the proposed model. Three relative parameters were selected as input variables to establish the EDZ prediction model, namely, $V(\mathrm{~m} / \mathrm{s})$, the angle between borehole and bedding $\left(A,{ }^{\circ}\right)$, and distance between section and working face $(D, \mathrm{~m})$. The relationship between the EDZ and other input variables is demonstrated in the correlation matrix plot in Figure 11, which shows the pairwise relationship between parameters along with corresponding correlation coefficients for each parameter. It can also be concluded that several parameters have relatively good/meaningful correlations with each other. Particularly, it can be seen that the parameter $A$ is highly correlated with the EDZ.

4.2. Random Forest Regression. Random forest regression is presently one of the most successful prediction methods. It is a tree-based and nonparametric ensemble technique that was proposed by Breiman [33, 35]. As a viable method for classification and regression, random forest can be applied to many engineering problems. Particularly, random forests have successfully been used in the fields of geotechnical and mining engineering, e.g., the prediction of rockburst in hard rock, pillar stability, tunnel-induced ground settlements, daily air surface temperature, and shear strength of rockfill materials [36-42]. Compared with traditional statistical methods utilizing a single standard regression tree, the RF uses a group of decision trees, such as a forest, to predict the results. In this study, the main aim is to predict the depth of an EDZ. As a nonparametric regression approach, $\mathrm{RF}$ is made up of a series of $W$ trees $\left\{\xi_{1}(X), \xi_{2}(X), \ldots, \xi_{K}(X)\right\}$, where $X=\left\{x_{1}, x_{2}, \ldots, x_{\beta}\right\}$ is a $\beta$-dimensional input parameter that forms a forest. The ensemble generates $P$ outputs related to each tree, $Y_{p}(p=1,2, \ldots, P)$. The final output is acquired through averaging all tree predictions. The training procedure is employed as follows [33, 35-42]:

(a) From the dataset, a bootstrap sample was drawn with a random sample.

(b) The bootstrap is used to evolve a tree with the following modifications: the best split within a randomly selected subset of mtry descriptors is chosen at each node. In the random forest algorithm, mtry plays the role of an essential tuning parameter. The tree grows to the maximum size and does not get pruned back.

(c) Step (b) is repeated until the number of trees (ntree) grows to a user defined number.

As for regression, random forest establishes an amount of $\mathrm{K}$ regression trees and averages the predicted results. The ultimate predicted values are achieved by the aggregation of all the individual trees that constitute the forest [35]. After growing to $W$ trees $\{\xi(x)\}$, the random forest regression predictor is calculated using the following equation:

$$
\varphi(x)=\frac{\sum_{w=1}^{W} \xi(x)}{W}
$$

To construct each regression tree, a new training set (bootstrap sample) is chosen from the original training set. Furthermore, in order to assess the prediction accuracy of random forests, about one-third of samples do not participate in establishing models and these data are also called out of bag (OOB) samples which can be used for evaluating the model error. In many studies, the OOB error is employed as an effective tool to evaluate the generalization error. 

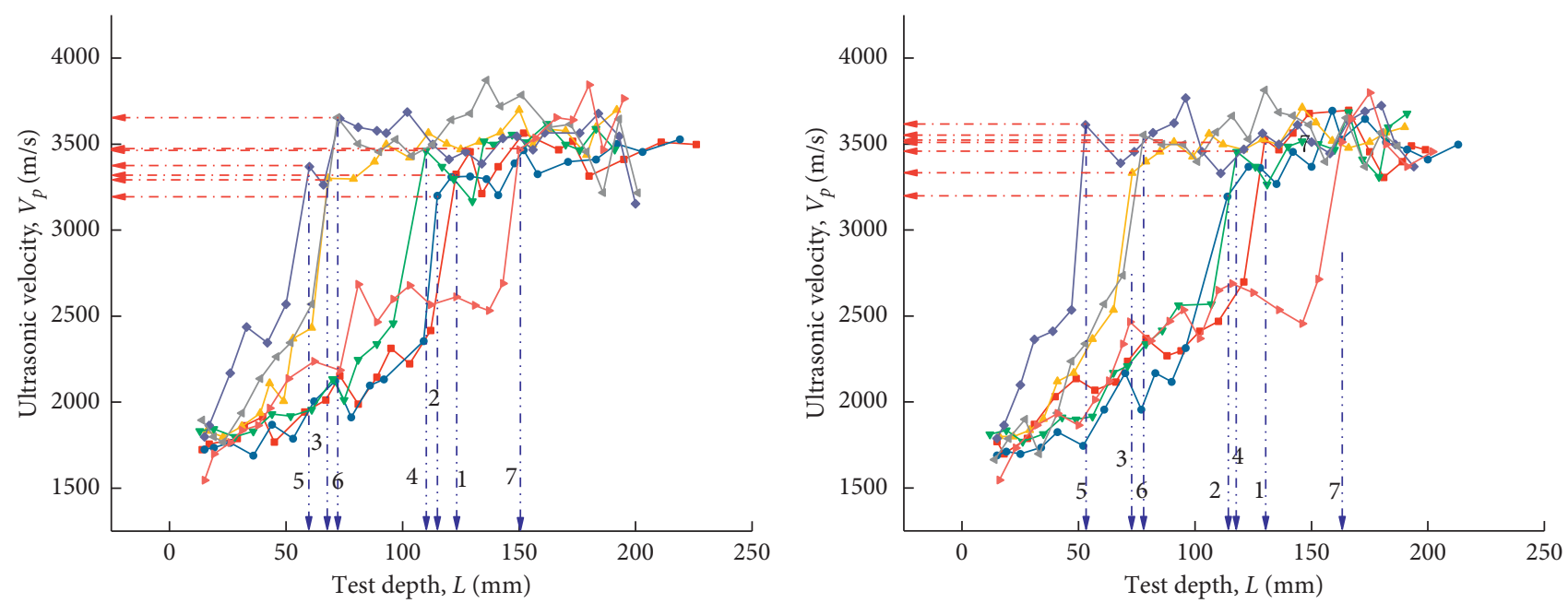

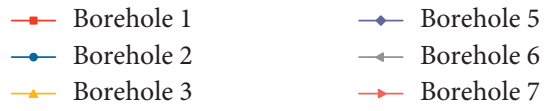

$\rightarrow$ Borehole 4

(a)

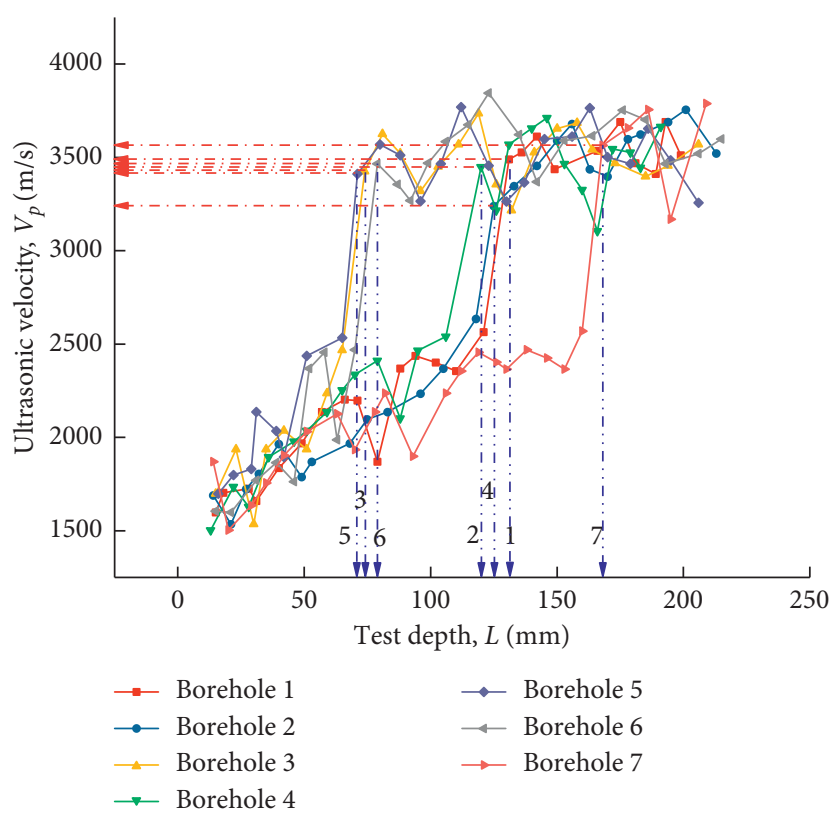

(c)

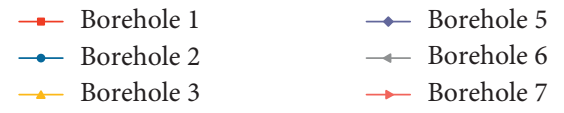

(b)

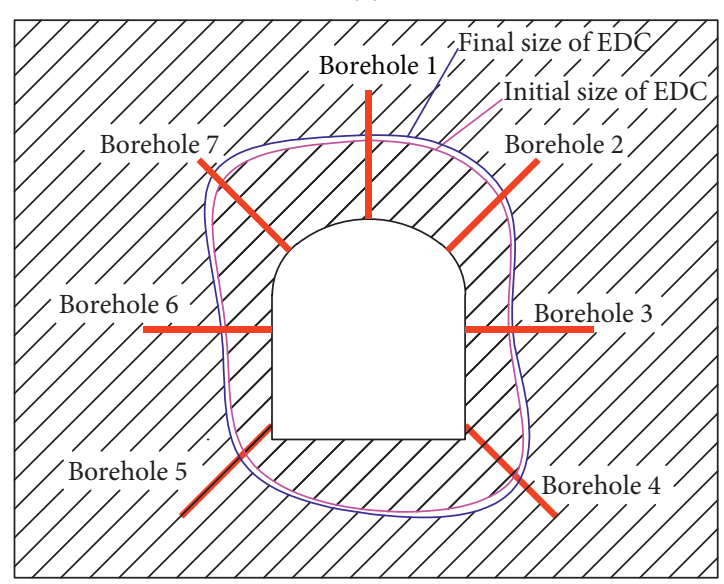

(d)

Figure 5: Relationship between $V_{p}$ and $L$ of different dates in Section 1: (a) test results on March 18, (b) test results on March 26, (c) test results on April 3, and (d) initial size and final size of the EDZ.

$$
\mathrm{GI}\left(\xi_{X(x i)}\right)=1-\sum_{j=1}^{m} \varphi\left(\xi_{X(x i)}, j\right)^{2}
$$

When independent test data are used, this built-in validation feature is able to improve the tree's generalization capability in the RF.

4.3. Performance Metric. Two common verification statistics [34-43], root-mean-square error (RMSE) and mean absolute error (MAE), are regularly employed to evaluate the performance of RF regression models. These metrics can be obtained by the following equations:

$$
\begin{aligned}
\mathrm{RMSE} & =\sqrt{\frac{\sum_{i=1}^{n}\left(y_{i}^{\mathrm{obs}}-y_{i}^{\mathrm{pred}}\right)^{2}}{n},} \\
\mathrm{MAE} & =\frac{\left(\sum_{i=1}^{n}\left|\left(1-y_{i}^{\mathrm{pred}}\right) / y_{i}^{\mathrm{obs}}\right|\right)}{n},
\end{aligned}
$$




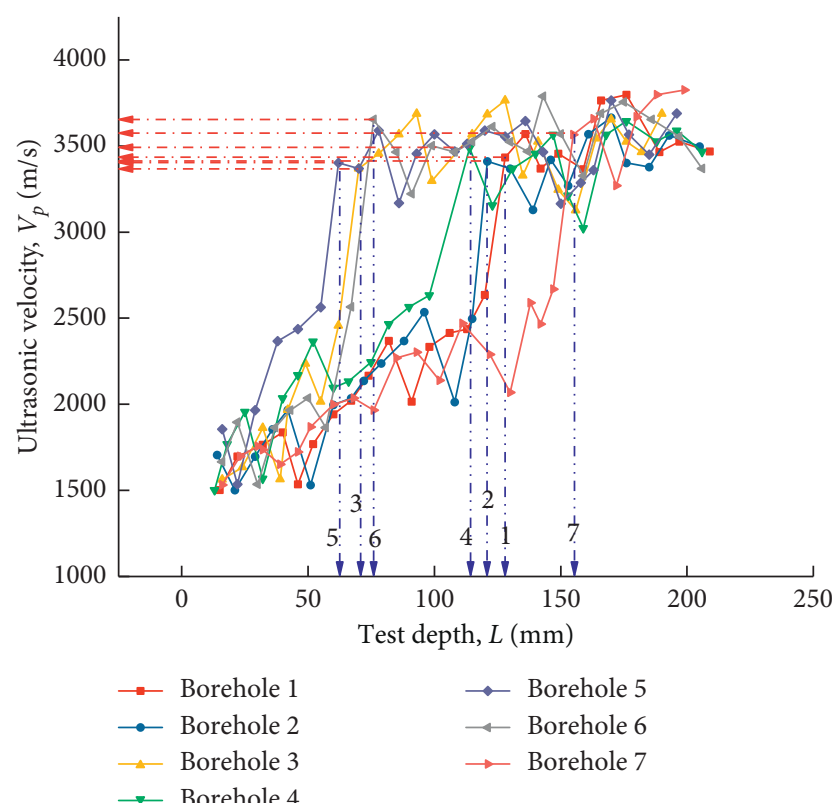

(a)

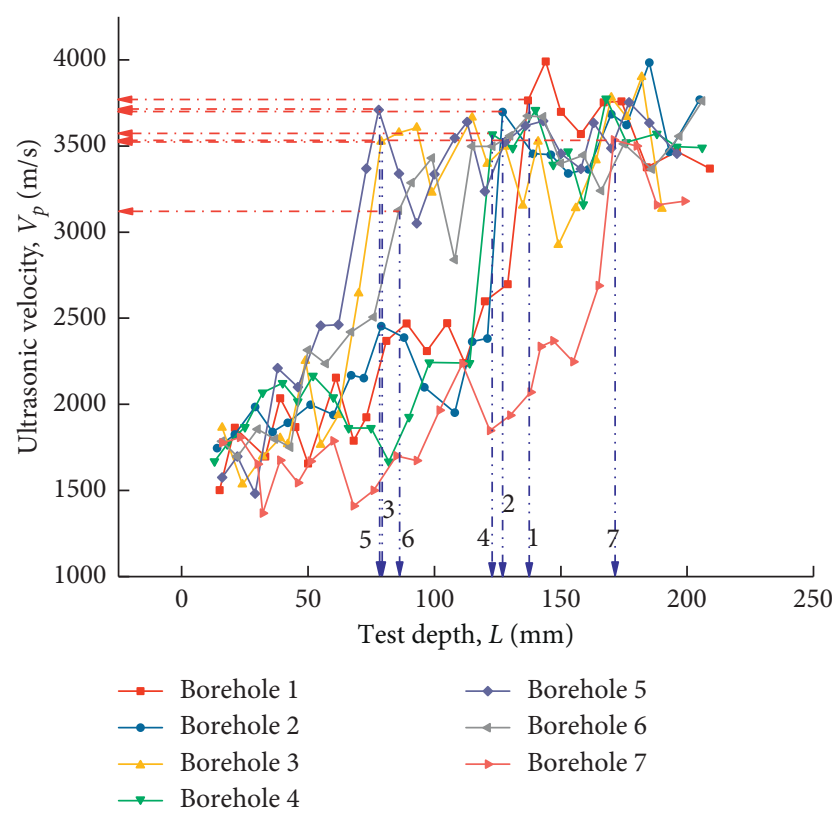

(c)

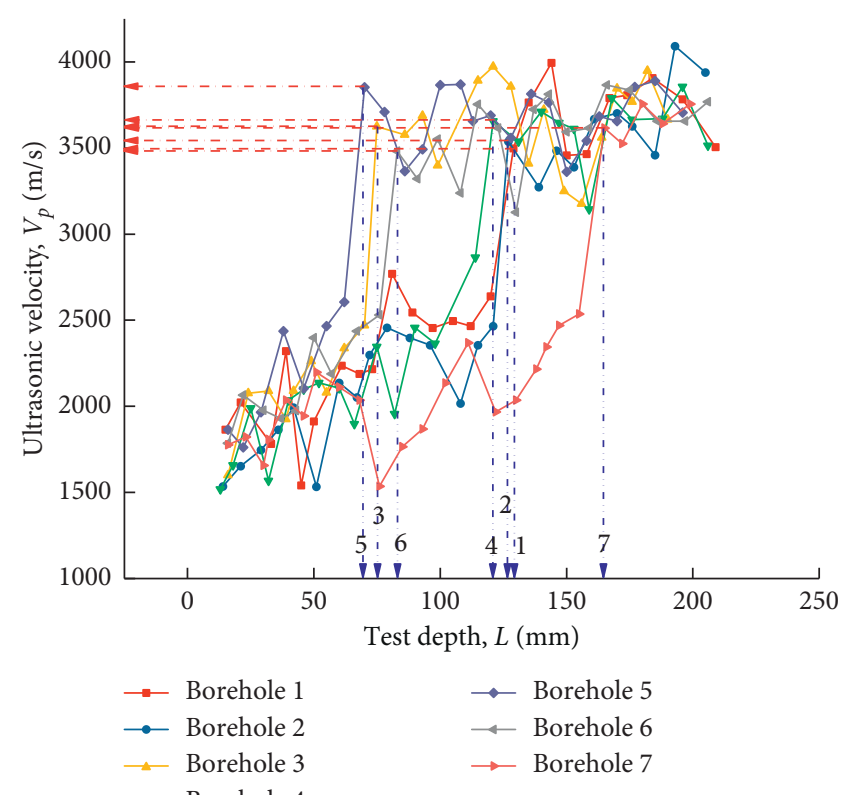

(b)

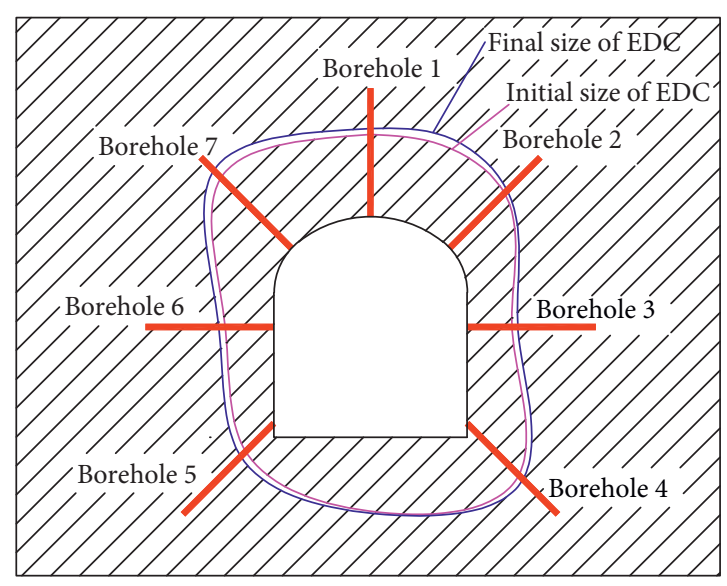

(d)

Figure 6: Relationship between $V_{p}$ and $L$ of different dates in Section 2: (a) test results on March 22, (b) test results on March 30, (c) test results on April 7, and (d) initial size and final size of the EDZ.

where $n$ is the total number of measured data points and $y_{i}^{\text {obs }}$ and $y_{i}^{\text {pred }}$ are the observed and predicted values of the $i$ th observation, respectively.

4.4. Results of Hyperparameter Tuning. In the process of the regression of the random forests, an approximate function is finally determined to predict the value of the output. First, the original datasets of EDZs are assigned randomly to either the training set or the test set. Among these, 47 sets of the available data are chosen as the training dataset. The remaining data are considered as the testing data. The test set is used for evaluating the accuracy of the function and estimating the performance of the regression model.

This section uses the abovementioned methodology for EDZ prediction. Input parameters $(A, V$, and $D)$ in the random forest models are the factors influencing an evaluation target (EDZ). To conduct the experiments, the 63 groups of data are randomly split into two subsets with a stratified sampling method that divides the datasets into training (47) and test (16) datasets. This method also creates 


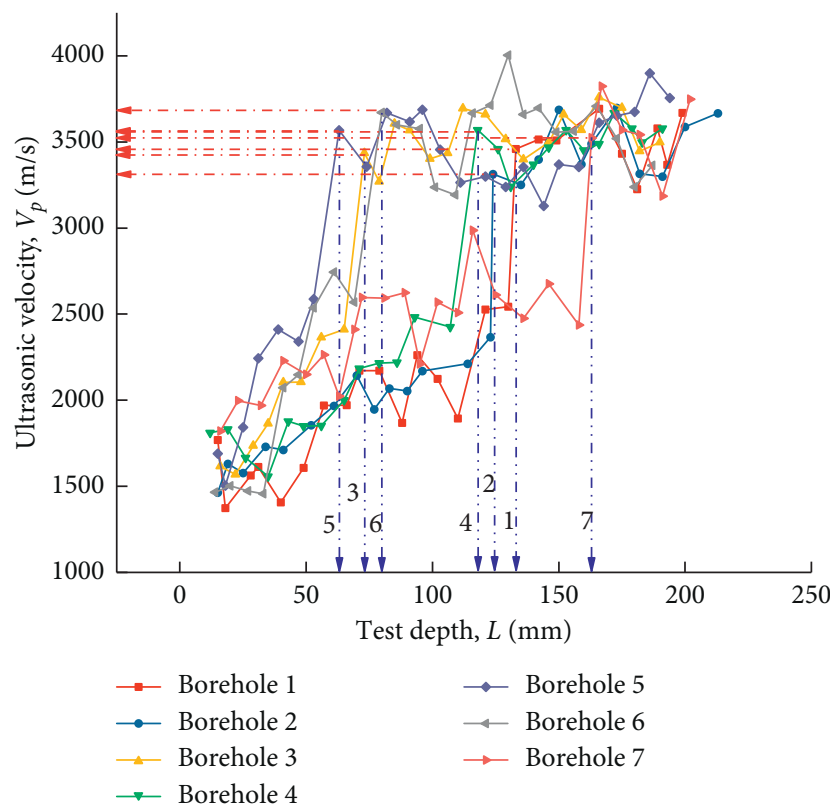

(a)

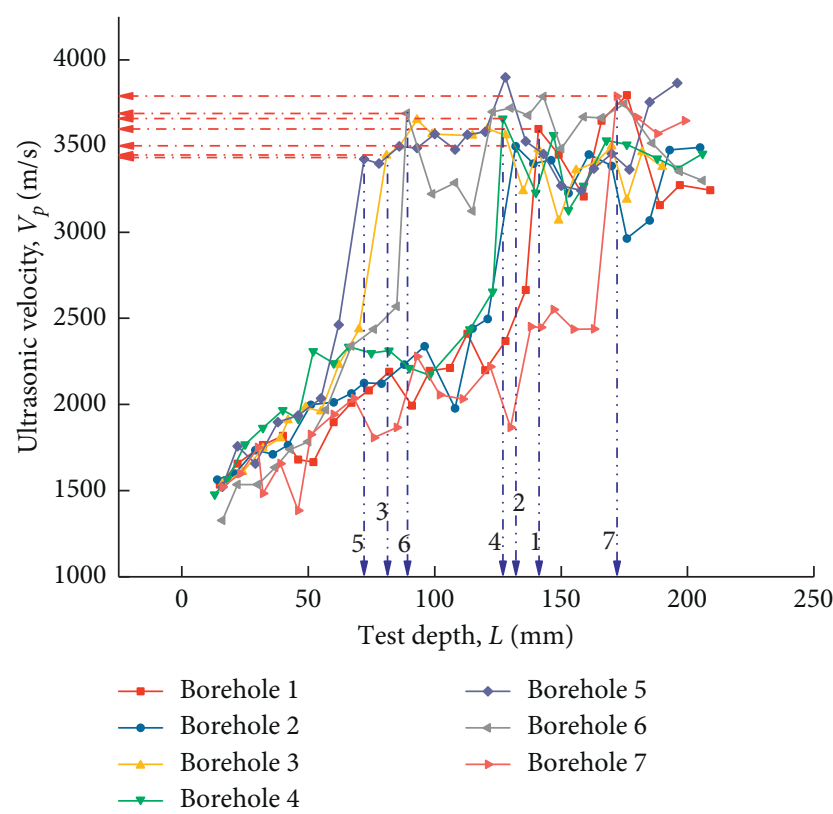

(c)

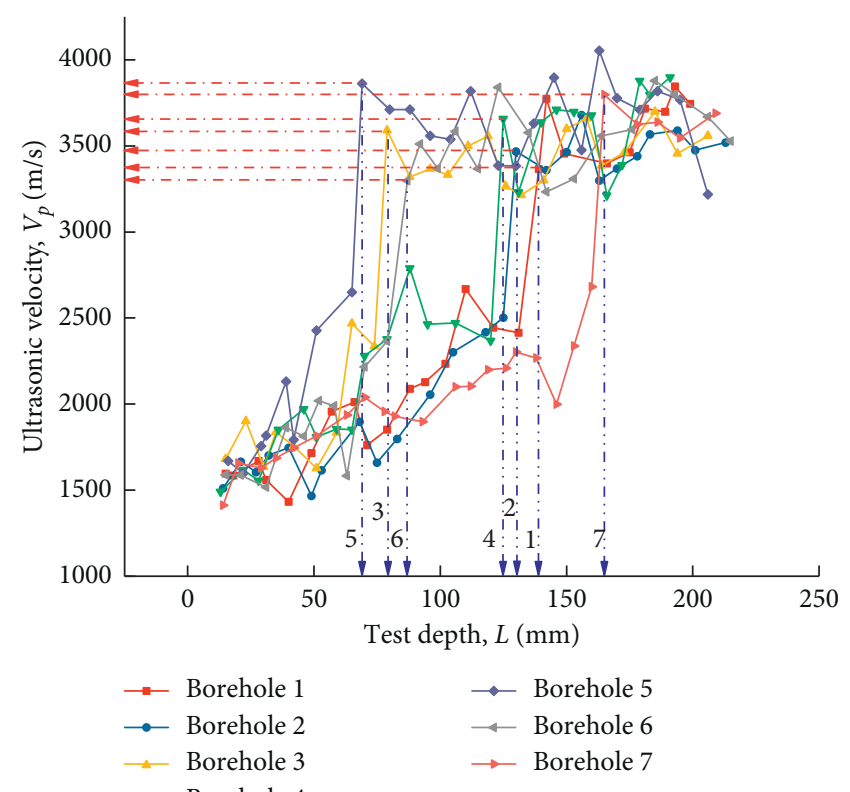

(b)

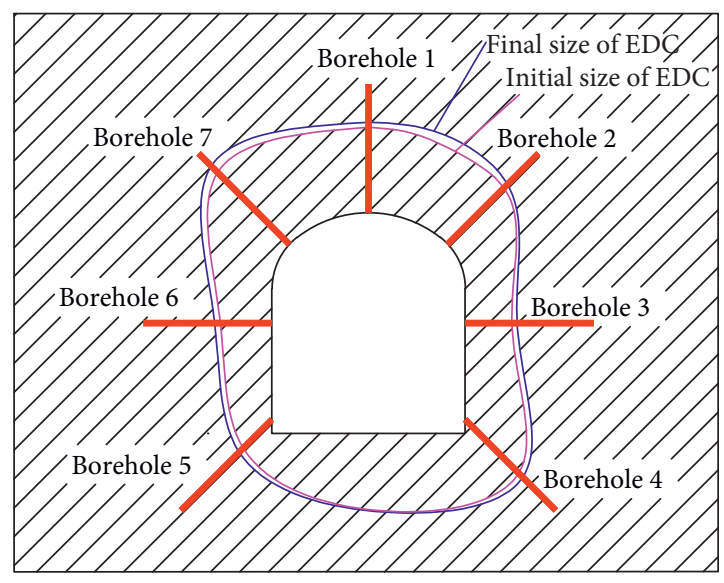

(d)

Figure 7: Relationship between $V_{p}$ and $L$ of different dates in Section 3: (a) test results on March 26, (b) test results on April 3, (c) test results on April 11, and (d) initial size and final size of the EDZ.

the training set by selecting from these subsets with the same outcome distribution as the whole dataset. Then, the training set is trained to establish a regression model that is used for evaluating the parameters for the random forest regression methods. To determine reasonable and optimized hyperparameters for the random forests, a fivefold CV procedure [20, 36-42] was implemented to determine the optimal parameter values based on the original training dataset. In addition, the $\operatorname{sqrt}(x)$ function was to be utilized to determine each node of the random tree where $x$ is the number of the input variables. In this study, we will stick to tuning two parameters, namely, the number of trees (ntree) and the number of variables randomly sampled as candidates at each split (mtry). These parameters have the following effect on our random forest model.

In the application of random forest experiments, the caret package [35] in $R$ was used to build a regression model. To investigate the behavior of the random forest hyperparameters (ntree and mtry), the model was tuned using a relatively fine search grid with CV methods, and tuning parameters were set as follows: $\operatorname{mtry}=c(1: 3)$, ntree $=\operatorname{seq}(50,1000$, by $=50)$. RMSE was used to select the 


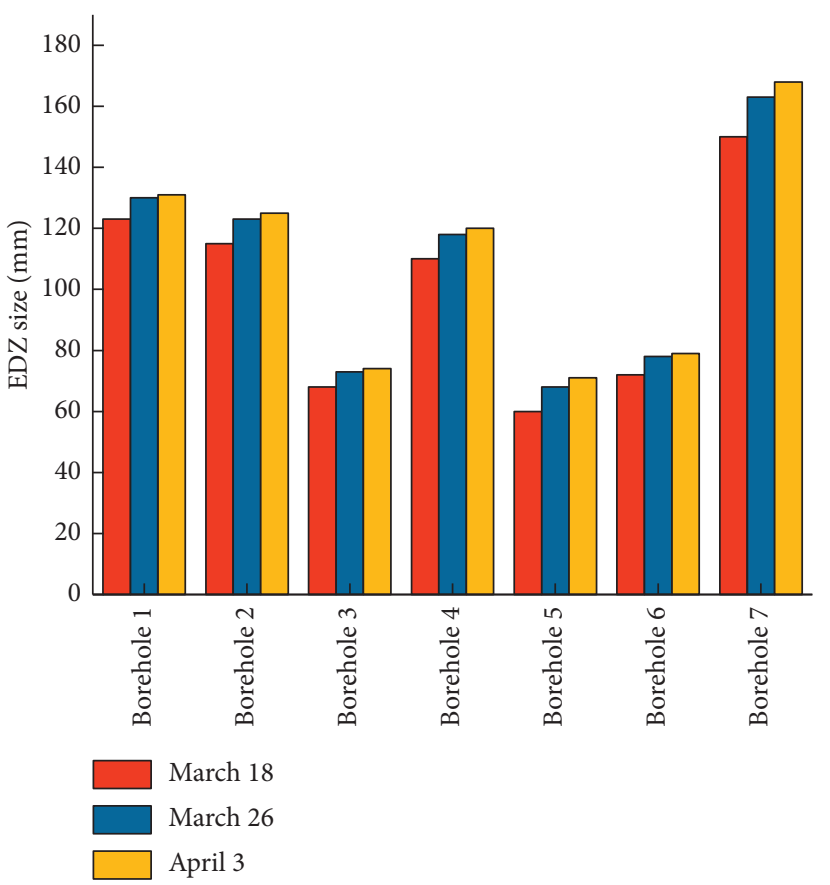

(a)

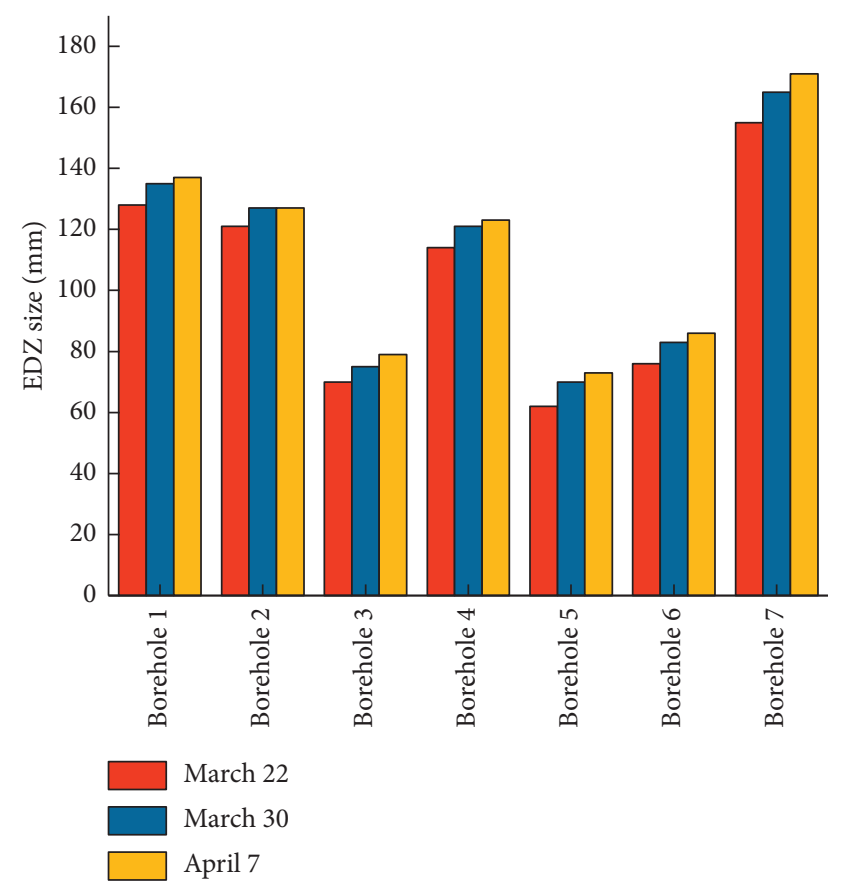

(b)

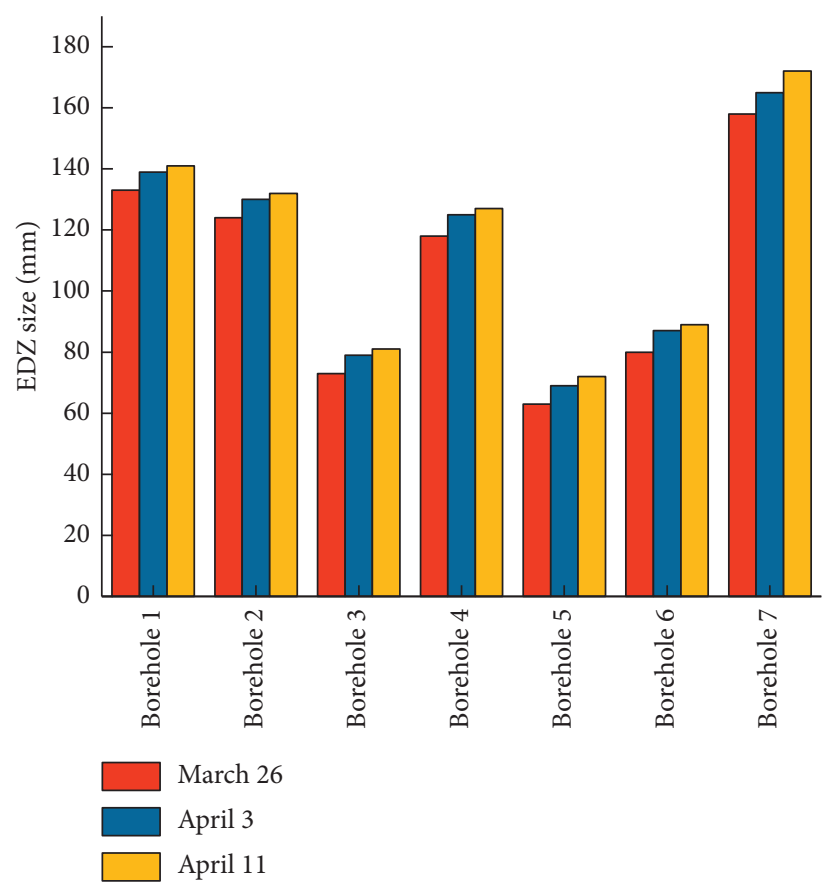

(c)

Figure 8: Time development laws for EDZ size.

optimal model using the smallest value. Figure 12 shows the cross-validated RMSE profile for the random forest. It can be seen that the RMSE value of the random forest model is more sensitive to mtry than to ntree. Thus, the final values used for the random forest model with a 5 -fold $\mathrm{CV}$ procedure (Figure 12) were ntree $=650$ and $\mathrm{mtry}=2$. The RMSE and MAE of the random forest model for 47 sets of training data were found to be 0.2499 and 0.2054 , respectively.
4.5. Results of Independent Test Set. To validate the predictive models based on the predicted and measured (real) values, 16 testing samples were validated by the optimized random forest model. The results are presented in Figure 13 and show actual vs. predicted EDZ by linear regression and random forest algorithm using the test data. Figure 13 suggests that all of the predicted values by random forest lie within $\pm 15 \%$ error off the line of perfect agreement. The RMSE and MAE between the observed and predicted values 


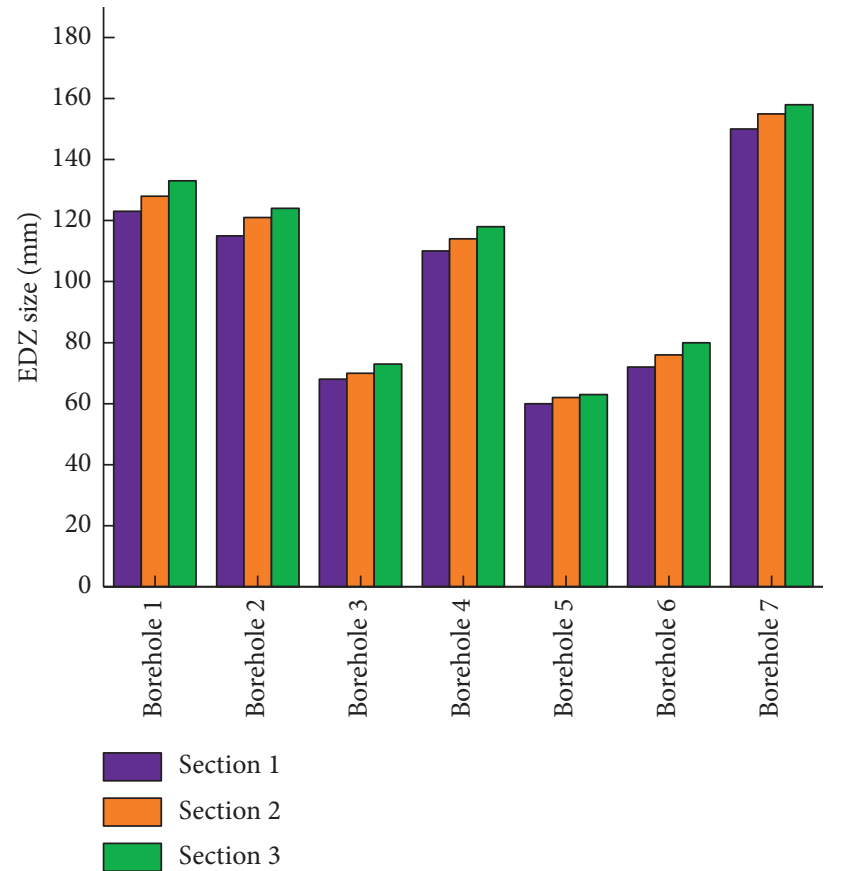

(a)

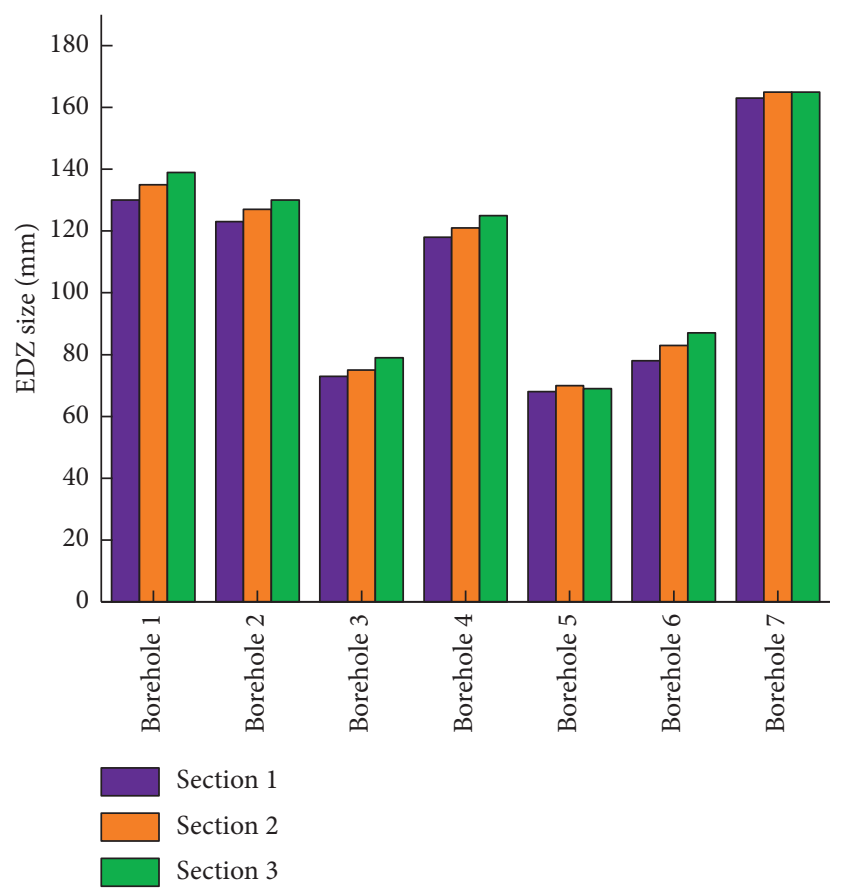

(b)

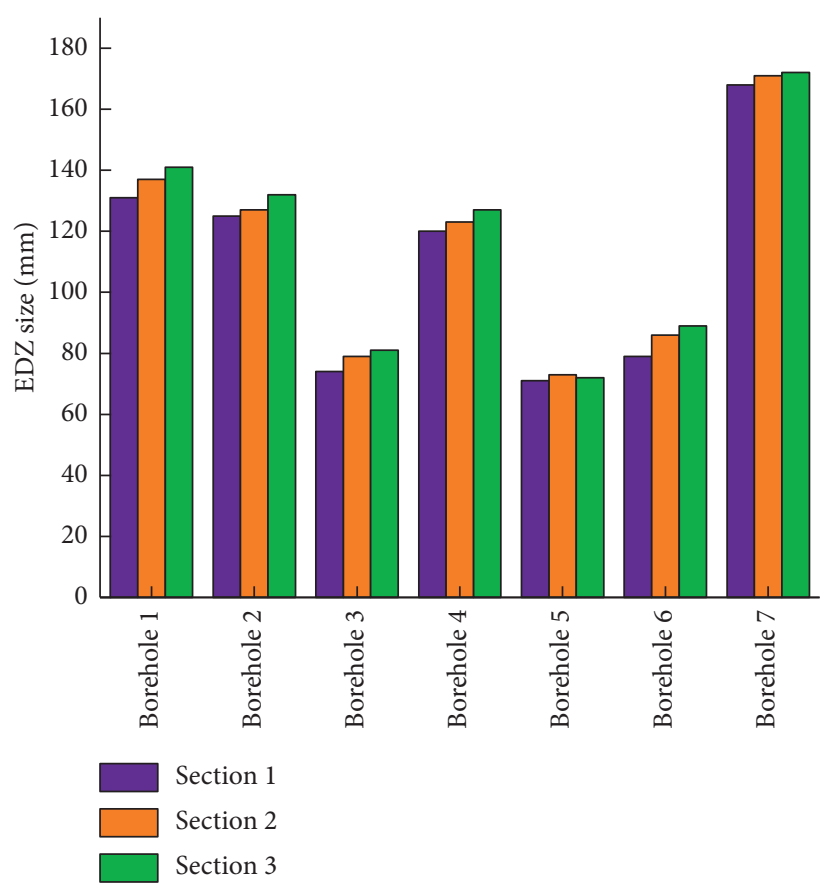

(c)

FIgURE 9: Space distribution laws for EDZ size.

of the random forest model are found to be 0.1613 and 0.1402 for test data, respectively. Additionally, the RMSE and MAE of the predicted values found using the conventional multiple linear regression method [34] were found to be 0.2075 and 0.1806 for test data, respectively. A comparison of RMSE and MAE values indicates improved performance by the random forest modeling approach compared to conventional multiple linear regression.
4.6. Variable Importance Analysis. The variable importance can be estimated easily by using $\operatorname{varImp}()$ for random forest models in the caret package [35]. Among all the three variables, it is noteworthy that $A$ is the most influential of the parameters among the indicators for prediction of EDZs, which is also consistent with the correlation matrix for the variables that showed the highest coefficients for these variables. The indicator $V$ is slightly sensitive. The factor $D$ is 


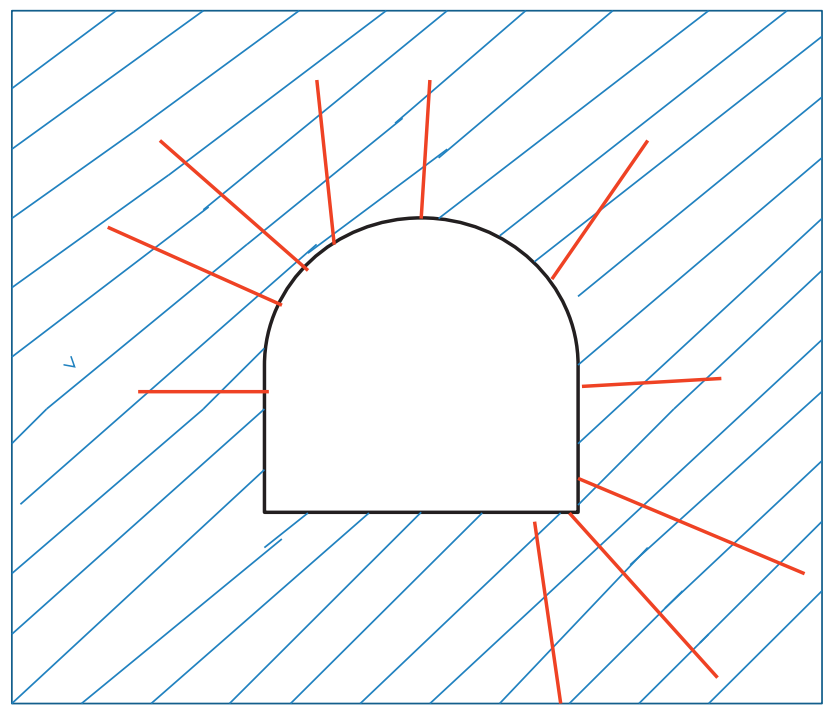

Figure 10: Asymmetric supporting technology.
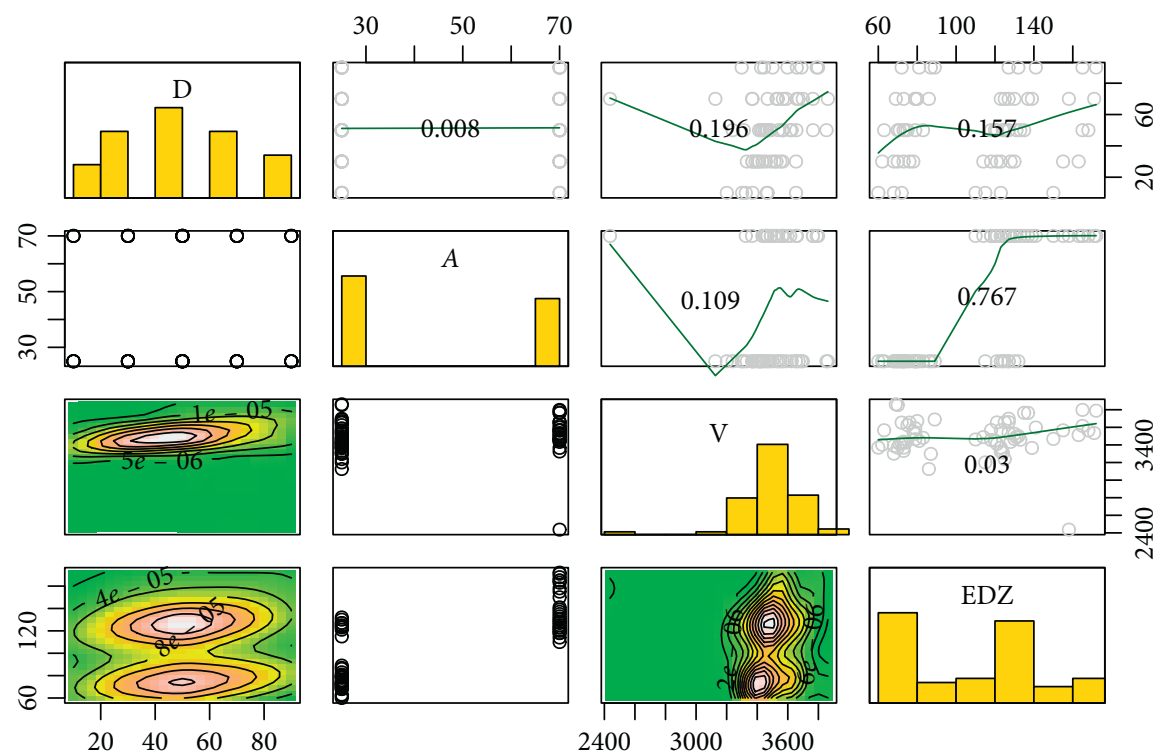

Figure 11: Correlation matrix plot of the original database.

not sensitive, and this means that this factor does not contribute to the aforementioned prediction modeling, as depicted in Figure 14. Note that the importance score for the random forest model relied on the dataset used in this work. In the future, a larger dataset is desirable to obtain more reliable importance scores for the influence of variables.

\section{Limitations}

The RF (random forest) approach for the size of EDZs, however, has some limitations that need to be improved in future research. First, the limitation of RF approach is that the datasets are relatively small, only a few dozen of cases involved in RF prediction model. A larger dataset related to EDZs is able to raise the model's performance and can improve the interpretability of variable importance scores. In this study, the variable importance score of $D$ is not sensitive, which is controversial to measured EDZ; a larger dataset is expected to make further explanation. Second, a further research about more influencing variables involving time after excavation needs to be explored and more hyperparameters need to be tuned to ensure the RF algorithm more feasible. Last, other advanced supervised machine learning approaches that have been proved to show excellent predictive performance on modeling complicated nonlinear engineering problems, such as support vector machine [44] and stochastic gradient boosting approach [45], have not been investigated and compared on the size of EDZs.

\section{Conclusions}

In this paper, according to field testing, the EDZ size of a roadway buried in a layered rock mass was analyzed. The main conclusions are as follows: 


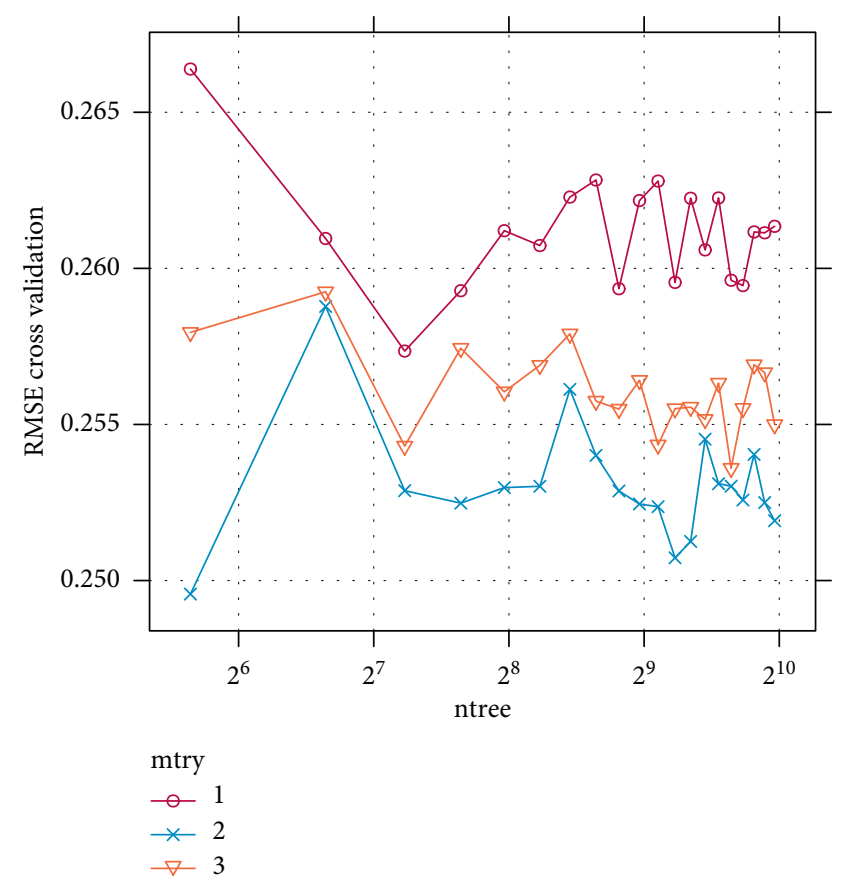

FIGURE 12: Fivefold cross-validated RMSE profiles for determining the optimal tuning parameters for random forest models.

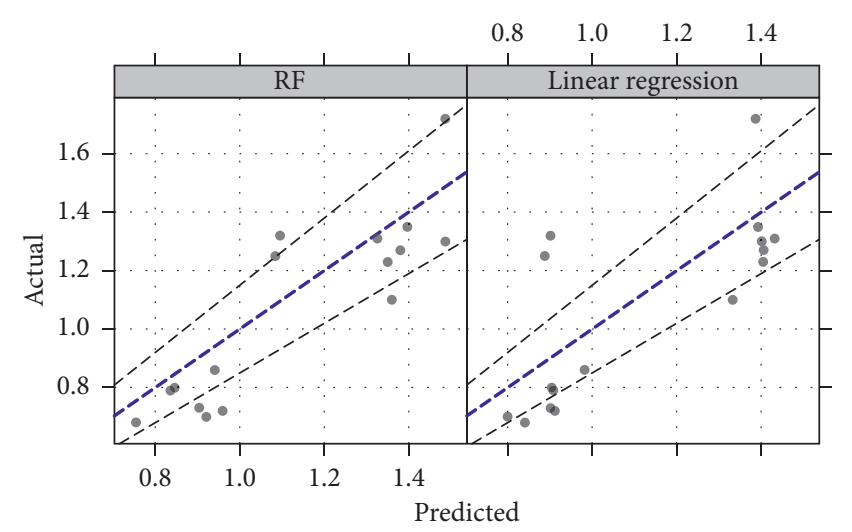

FIGURE 13: Error in EDZ prediction using random forests and linear regression methods for the test set.

(1) The excavation damaged zone of an underground roadway is affected by several factors. First, the excavation blasting dynamic load and the unloading effect are the main reasons that the initial EDZ is induced. Subsequent to this, the stress concentration can enlarge the size of the EDZ and the increment of the EDZ limit.

(2) There is an asymmetric distribution regulation of EDZs in the layer rocks, and the size of the EDZ increases by approximately $5 \%-18 \%$ with the excavation progress of roadway. In addition, the later excavation zone has a comparatively larger value.

(3) It is necessary to design the supporting parameters according to the distribution of the EDZ, that is, an asymmetric supporting technology is necessary to

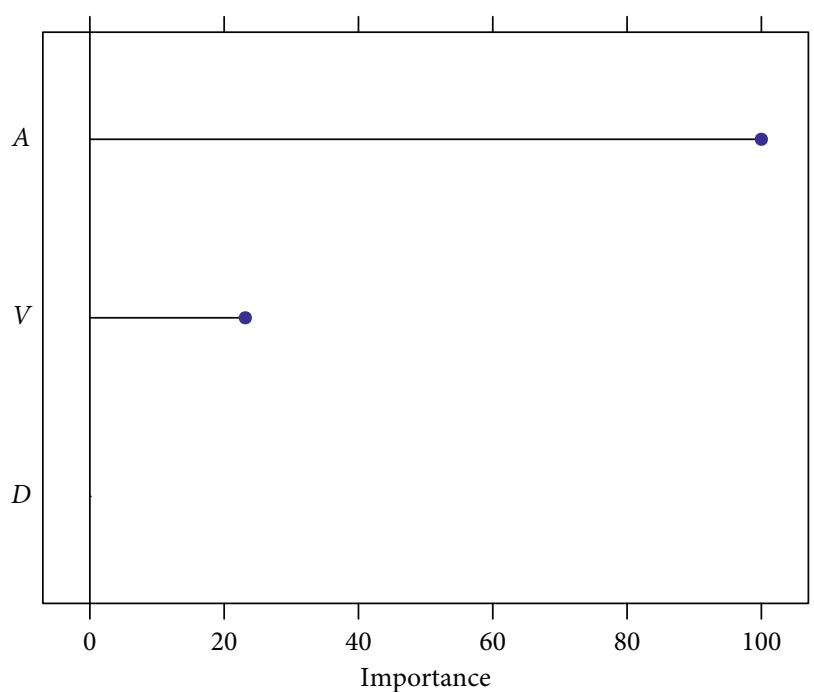

FIGURE 14: Variable importance scores for three predictors used in the random forest models for EDZ prediction.

maintain the stability of roadways buried in layer rocks.

(4) Compared with conventional multiple linear regression, it can be concluded that random forest regression algorithms perform well in predicting the EDZ in terms of its explanatory value and error. Random forest algorithms can effectively identify useful input parameters which affect EDZs.

\section{Data Availability}

The data used to support the findings of this study are available from the corresponding author upon request.

\section{Conflicts of Interest}

The authors declare that they have no conflicts of interest.

\section{Acknowledgments}

The authors would like to acknowledge the financial support of National Natural Science Foundation of China (no. 51774058) and supported by the Chongqing Basic Research and Frontier Exploration Project (cstc2018jcyjA3320 and cstc2016jcyjA1861), which are gratefully acknowledged.

\section{References}

[1] X. Li, J. Zhou, S. Wang, and B. Liu, "Review and practice of deep mining for solid mineral resources," Chin J Nonferrous Metals, vol. 27, no. 7, pp. 1236-1262, 2017.

[2] K. Du, M. Tao, X.-B. Li, and J. Zhou, "Experimental study of slabbing and rockburst induced by true-triaxial unloading and local dynamic disturbance," Rock Mechanics and Rock Engineering, vol. 49, no. 9, pp. 3437-3453, 2016.

[3] M. Tao, Z. W. Li, W. Z. Cao, X. B. Li, and C. Q. Wu, "Stress redistribution of dynamic loading incident with arbitrary waveform through a circular cavity," International Journal for 
Numerical and Analytical Methods in Geomechanics, vol. 43, no. 6, pp. 1279-1299, 2019.

[4] J. Zhou, X. Li, and H. S. Mitri, "Evaluation method of rockburst: state-of-the-art literature review," Tunnelling and Underground Space Technology, vol. 81, pp. 632-659, 2018.

[5] M. Tao, H. Zhao, X. Li, X. Li, and K. Du, "Failure characteristics and stress distribution of pre-stressed rock specimen with circular cavity subjected to dynamic loading," Tunnelling and Underground Space Technology, vol. 81, pp. 1-15, 2018.

[6] S. Wang, X. Li, K. Du, S. Wang, and M. Tao, "Experimental study of the triaxial strength properties of hollow cylindrical granite specimens under coupled external and internal confining stresses," Rock Mechanics and Rock Engineering, vol. 51, no. 7, pp. 2015-2031, 2018.

[7] M. Tao, A. Ma, W. Cao, X. Li, and F. Gong, "Dynamic response of pre-stressed rock with a circular cavity subject to transient loading," International Journal of Rock Mechanics and Mining Sciences, vol. 99, pp. 1-8, 2017.

[8] J. Zhou, X. Li, and X. Shi, "Long-term prediction model of rockburst in underground openings using heuristic algorithms and support vector machines," Safety Science, vol. 50, no. 4, pp. 629-644, 2012.

[9] K. Du, R. Su, M. Tao, C. Yang, A. Momeni, and S. Wang, "Specimen shape and cross-section effects on the mechanical properties of rocks under uniaxial compressive stress," Bulletin of Engineering Geology and the Environment, pp. 1-14, 2019.

[10] E. T. Brown and E. Hoek, "Trends in relationships between measured in situ stresses and depth," International Journal of Rock Mechanics and Mining Sciences of Geomechanics Abstracts, vol. 15, no. 4, pp. 211-215, 1978.

[11] K. Du, X.-B. Li, D.-Y. Li, and L. Weng, "Failure properties of rocks in true triaxial unloading compressive test," Transactions of Nonferrous Metals Society of China, vol. 25, no. 2, pp. 571-581, 2015.

[12] J. H. Yang, Q. H. Jiang, Q. B. Zhang, and J. Zhao, "Dynamic stress adjustment and rock damage during blasting excavation in a deep-buried circular tunnel," Tunnelling and Underground Space Technology, vol. 71, pp. 591-604, 2018.

[13] R. S. Read, "20 years of excavation response studies at AECL's underground research laboratory," International Journal of Rock Mechanics and Mining Sciences, vol. 41, no. 8, pp. 1251-1275, 2004.

[14] H. Fattahi, M. A. E. Farsangi, S. Shojaee, and H. Mansouri, "Selection of a suitable method for the assessment of excavation damage zone using fuzzy AHP in Aba Saleh Almahdi tunnel, Iran," Arabian Journal of Geosciences, vol. 8, no. 5, pp. 2863-2877, 2015.

[15] J. Yang, W. Chen, W. Zhao et al., "Geohazards of tunnel excavation in interbedded layers under high in situ stress," Engineering Geology, vol. 230, pp. 11-22, 2017.

[16] M. Wang, X. Shi, and J. Zhou, "Optimal charge scheme calculation for multiring blasting using modified Harries mathematical model," Journal of Performance of Constructed Facilities, vol. 33, no. 2, article 04019002, 2019.

[17] M. Wang, X. Shi, J. Zhou, and X. Qiu, "Multi-planar detection optimization algorithm for the interval charging structure of large-diameter longhole blasting design based on rock fragmentation aspects," Engineering Optimization, vol. 50, no. 12, pp. 2177-2191, 2018.

[18] M. Wang, X. Shi, and J. Zhou, "Charge design scheme optimization for ring blasting based on the developed scaled Heelan model," International Journal of Rock Mechanics and Mining Sciences, vol. 110, pp. 199-209, 2018.
[19] M. Mohammadi and H. Tavakoli, "Comparing the generalized Hoek-Brown and Mohr-Coulomb failure criteria for stress analysis on the rocks failure plane," Geomechanics and Engineering, vol. 9, no. 1, pp. 115-124, 2015.

[20] Q. Zhang, C. Li, M. Min, B. Jiang, and L. Yu, "Elastoplastic analysis of circular openings in elasto-brittle-plastic rock mass based on logarithmic strain," Mathematical Problems in Engineering, vol. 2017, Article ID 7503912, 9 pages, 2017.

[21] S. Roateşi, "Analytical and numerical approach for tunnel face advance in a viscoplastic rock mass," International Journal of Rock Mechanics and Mining Sciences, vol. 70, pp. 123-132, 2014.

[22] P. Fritz, "An analytical solution for axisymmetric tunnel problems in elasto-viscoplastic media," International Journal for Numerical and Analytical Methods in Geomechanics, vol. 8, no. 4, pp. 325-342, 1984.

[23] J. Shen and M. Karakus, "Three-dimensional numerical analysis for rock slope stability using shear strength reduction method," Canadian Geotechnical Journal, vol. 51, no. 2, pp. 164-172, 2014.

[24] A. Siahmansouri, J. Gholamnejad, and M. F. Marji, "A hybridized numerical and regression method for estimating the minimum rock pillar width of twin circular tunnels," Arabian Journal of Geosciences, vol. 7, no. 3, pp. 1059-1066, 2014.

[25] J. Yang, W. Lu, Y. Hu, M. Chen, and P. Yan, "Numerical simulation of rock mass damage evolution during deepburied tunnel excavation by drill and blast," Rock Mechanics and Rock Engineering, vol. 48, no. 5, pp. 2045-2059, 2015.

[26] H. Q. Yang, Y. Y. Zeng, Y. F. Lan, and X. P. Zhou, “Analysis of the excavation damaged zone around a tunnel accounting for geostress and unloading," International Journal of Rock Mechanics and Mining Sciences, vol. 69, pp. 59-66, 2014.

[27] M. A. Perras and M. S. Diederichs, "Predicting excavation damage zone depths in brittle rocks," Journal of Rock Mechanics and Geotechnical Engineering, vol. 8, no. 1, pp. 60-74, 2016.

[28] W. C. Zhu and O. T. Bruhns, "Simulating excavation damaged zone around a circular opening under hydromechanical conditions," International Journal of Rock Mechanics and Mining Sciences, vol. 45, no. 5, pp. 815-830, 2008.

[29] E. Hoek and E. T. Brown, "Practical estimates of rock mass strength," International Journal of Rock Mechanics and Mining Sciences \& Geomechanics Abstracts, vol. 34, no. 8, pp. 1165-1186, 1997.

[30] M. Cai, P. K. Kaiser, Y. Tasaka, T. Maejima, H. Morioka, and M. Minami, "Generalized crack initiation and crack damage stress thresholds of brittle rock masses near underground excavations," International Journal of Rock Mechanics and Mining Sciences, vol. 41, no. 5, pp. 833-847, 2004.

[31] H. Wang, Y. Jiang, S. Xue et al., "Assessment of excavation damaged zone around roadways under dynamic pressure induced by an active mining process," International Journal of Rock Mechanics and Mining Sciences, vol. 77, pp. 265-277, 2015.

[32] F. Wu, J. Liu, T. Liu, H. Zhuang, and C. Yan, "A method for assessment of excavation damaged zone (EDZ) of a rock mass and its application to a dam foundation case," Engineering Geology, vol. 104, no. 3-4, pp. 254-262, 2009.

[33] L. Breiman, "Random forests," Machine Learning, vol. 45, no. 1, pp. 5-32, 2001.

[34] J. Zhou and X. B. Li, "Evaluating the thickness of broken rock zone for deep roadways using nonlinear SVMs and multiple linear regression model," Procedia Engineering, vol. 26, pp. 972-981, 2011. 
[35] M. Kuhn and K. Johnson, Applied Predictive Modeling, Springer, New York, USA, 2013.

[36] J. Zhou, X. B Li, and H. S. Mitri, "Classification of rockburst in underground projects: comparison of ten supervised learning methods," Journal of Computing in Civil Engineering, vol. 30, no. 5, article 04016003, 2016.

[37] S. Adusumilli, D. Bhatt, H. Wang, P. Bhattacharya, and V. Devabhaktuni, "A low-cost INS/GPS integration methodology based on random forest regression," Expert Systems with Applications, vol. 40, no. 11, pp. 4653-4659, 2013.

[38] J. Zhou, X. Z. Shi, K. Du, X. Y. Qiu, X. B. Li, and H. S. Mitri, "Feasibility of random-forest approach for prediction of ground settlements induced by the construction of a shielddriven tunnel," International Journal of Geomechanics, vol. 17, no. 6, article 04016129, 2017.

[39] J. Zhou, X. Li, and H. S. Mitri, “Comparative performance of six supervised learning methods for the development of models of hard rock pillar stability prediction," Natural Hazards, vol. 79, no. 1, pp. 291-316, 2015.

[40] S. Ferlito, G. Adinolfi, and G. Graditi, "Comparative analysis of data-driven methods online and offline trained to the forecasting of grid-connected photovoltaic plant production," Applied Energy, vol. 205, pp. 116-129, 2017.

[41] J. Zhou, E. Li, H. Wei, C. Li, Q. Qiao, and D. J. Armaghani, "Random forests and cubist algorithms for predicting shear strengths of rockfill materials," Applied Sciences, vol. 9, no. 8, p. 1621, 2019.

[42] P. Noi, J. Degener, and M. Kappas, "Comparison of multiple linear regression, cubist regression, and random forest algorithms to estimate daily air surface temperature from dynamic combinations of MODIS LST data," Remote Sensing, vol. 9, no. 5, p. 398, 2017.

[43] J. Zhou, A. Nekouie, C. A. Arslan, B. T. Pham, and M. Hasanipanah, "Novel approach for forecasting the blastinduced AOp using a hybrid fuzzy system and firefly algorithm," Engineering with Computers, pp. 1-10, 2019.

[44] X.-Z. Shi, J. Zhou, B.-B. Wu, D. Huang, and W. Wei, "Support vector machines approach to mean particle size of rock fragmentation due to bench blasting prediction," Transactions of Nonferrous Metals Society of China, vol. 22, no. 2, pp. 432-441, 2012.

[45] J. Zhou, E. Li, M. Wang, X. Chen, X. Shi, and L. Jiang, "Feasibility of stochastic gradient boosting approach for evaluating seismic liquefaction potential based on SPT and CPT case histories," Journal of Performance of Constructed Facilities, vol. 33, no. 3, article 04019024, 2019. 


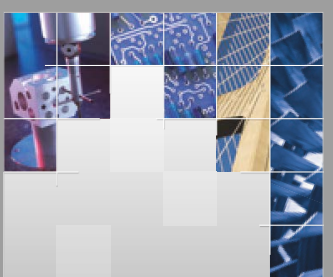

\section{Enfincering}
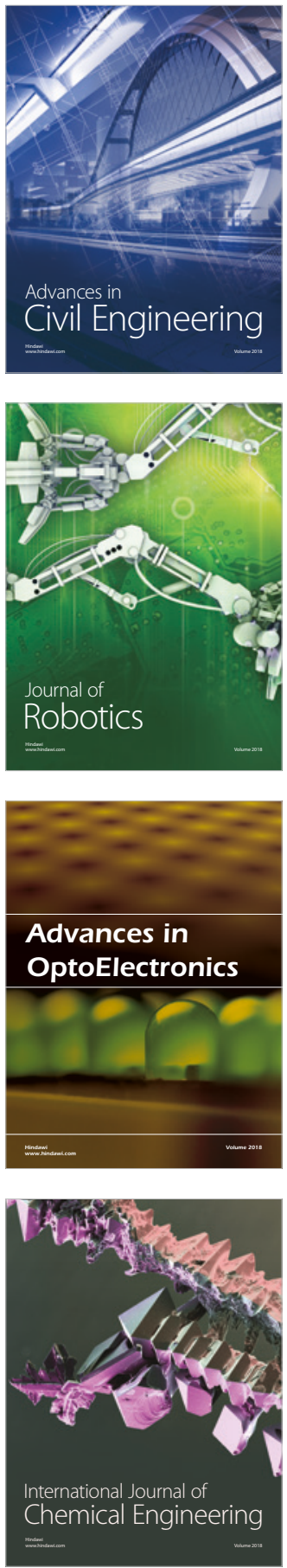

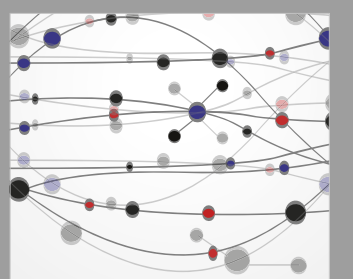

\section{Rotating \\ Machinery}

The Scientific World Journal

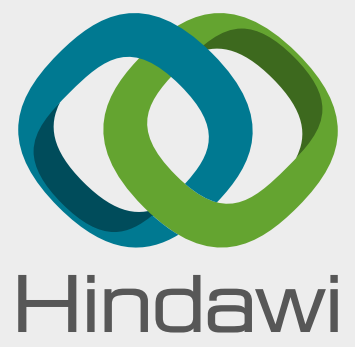

Submit your manuscripts at

www.hindawi.com
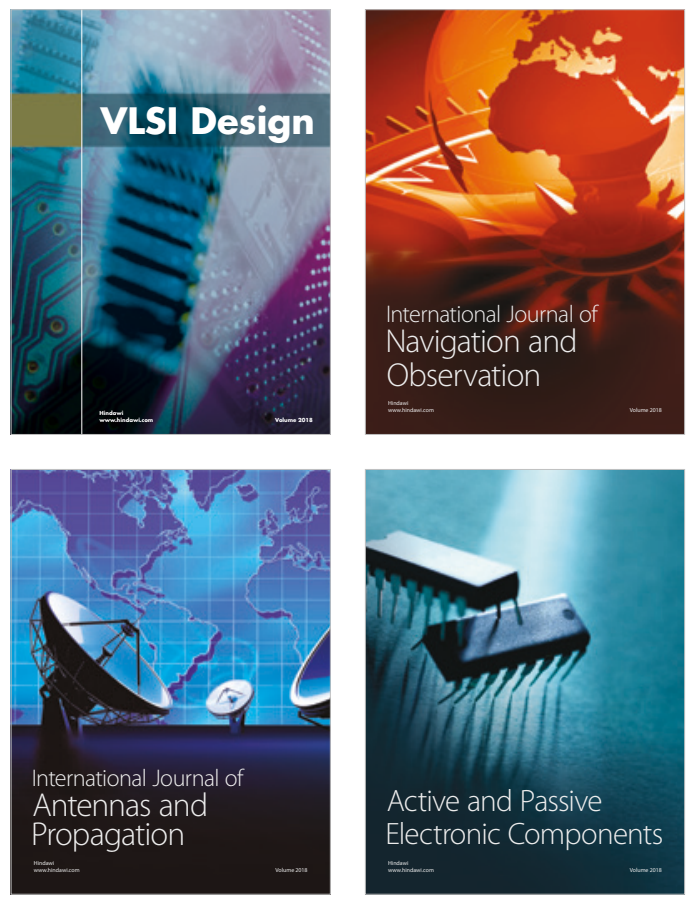
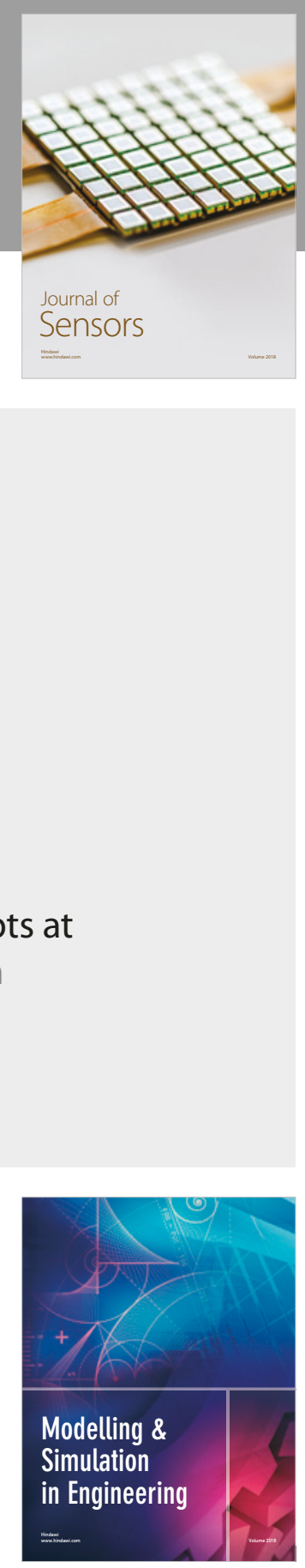

\section{Advances \\ Multimedia}
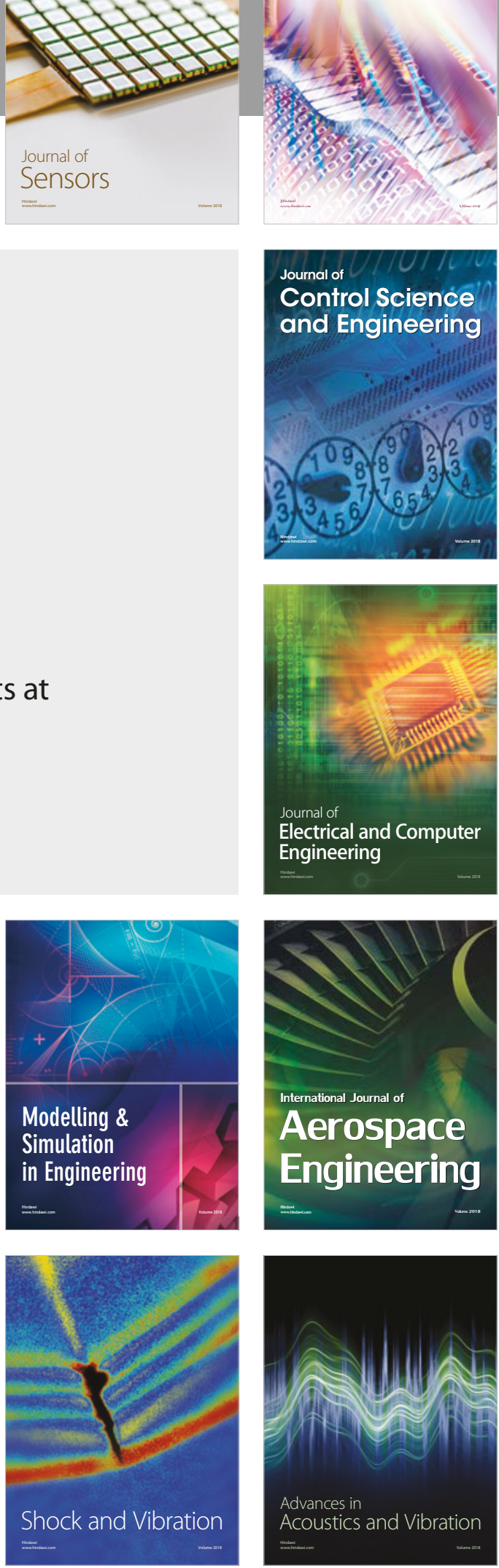